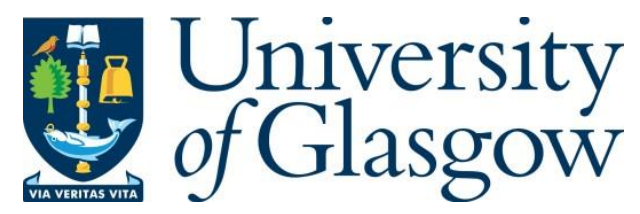

Song, Y.-F., Zhang, W., Wang, Z., Zhao, Y. and Miras, H. N. (2019) Precise control of the oriented layered double hydroxide nanosheets growth on graphene oxides leading to efficient catalysts for cascade reactions. ChemCatChem, 11(22), pp. 5466-5474.

There may be differences between this version and the published version. You are advised to consult the publisher's version if you wish to cite from it.

This is the peer reviewed version of the following article, Song, Y.-F., Zhang, W., Wang, Z., Zhao, Y. and Miras, H. N. (2019) Precise control of the oriented layered double hydroxide nanosheets growth on graphene oxides leading to efficient catalysts for cascade reactions. ChemCatChem, 11(22), pp. 5466-5474, which has been published in final form at http://dx.doi.org/10.1002/cctc.201901208

This article may be used for non-commercial purposes in accordance with Wiley Terms and Conditions for Self-Archiving.

http://eprints.gla.ac.uk/195048/

Deposited on: 31 October 2019

Enlighten - Research publications by members of the University of Glasgow http://eprints.gla.ac.uk 
Heterogeneous \& Homogeneous \& Bio- \& NanoCHEMCATCHEM CATALYSIS

\section{Accepted Article}

Title: Precise control of the oriented layered double hydroxide nanosheets growth on graphene oxides leading to efficient catalysts for cascade reactions

Authors: Yu-Fei Song, Wei Zhang, Zelin Wang, Yufei Zhao, and Haralampos N. Miras

This manuscript has been accepted after peer review and appears as an Accepted Article online prior to editing, proofing, and formal publication of the final Version of Record (VoR). This work is currently citable by using the Digital Object Identifier (DOI) given below. The VoR will be published online in Early View as soon as possible and may be different to this Accepted Article as a result of editing. Readers should obtain the VoR from the journal website shown below when it is published to ensure accuracy of information. The authors are responsible for the content of this Accepted Article.

To be cited as: ChemCatChem 10.1002/cctc.201901208

Link to VoR: http://dx.doi.org/10.1002/cctc.201901208 


\title{
Precise control of the oriented layered double hydroxide nanosheets growth on graphene oxides leading to efficient catalysts for cascade reactions
}

Wei Zhang, ${ }^{a}$ Zelin Wang, ${ }^{a}$ Yufei Zhao, ${ }^{a}$ Haralampos N. Miras, ${ }^{\text {t* }}$ and Yu-Fei Song ${ }^{a^{*}}$

[a] W. Zhang, Z. Wang, Prof. Y. Zhao and Prof. Y.-F. Song*

State Key Laboratory of Chemical Resource Engineering, Beijing Advanced Innovation Center for Soft Matter Science and Engineering, Beijing University of Chemical Technology, Beijing 100029, P. R. China. *Email: songyf@mail.buct.edu.cn; Tel/Fax: +86 10- 64431832

[b] Dr. H. N. Miras

WestCHEM, School of Chemistry, University of Glasgow, Glasgow G12 8QQ, U.K.

*E-mail: charalampos.moiras@glasgow.ac.uk; Tel: +44 (0)141-3304375

\begin{abstract}
In recent years, great attention has been paid to cascade reactions, which can improve efficiency and reduce waste production by implementing several consecutive reactions. Herein, two bifunctional catalysts were successfully prepared by precise control of the oriented layered double hydroxides ( $\mathrm{LDHs}$ ) growth on graphene oxides (GO) using a single-drop and co-precipitation method, respectively. The resultant Ru/LDH-GO-P and Ru/LDH-GO-V composites were characterized by EXAFS, FT-IR, XRD, TG-DTA, BET, XPS, TEM, $\mathrm{CO}_{2}-\mathrm{TPD}, \mathrm{O}_{2}-\mathrm{TPD}$, etc. The catalytic performance of Ru/LDH-GO-P and $\mathrm{Ru} / \mathrm{LDH}-\mathrm{GO}-\mathrm{V}$ for one-pot oxidation-Knoevenagel condensation reaction showed significant difference under the same experimental conditions, in which the $\mathrm{Ru} / \mathrm{LDH}-\mathrm{GO}-\mathrm{P}$ showed $99 \%$ conversion and $99 \%$ selectivity, in marked contrast of $60.7 \%$ conversion and $47.9 \%$ selectivity using $\mathrm{Ru} / \mathrm{LDH}-\mathrm{GO}-\mathrm{V}$ as catalyst. The large enhancement of the catalytic performance using $\mathrm{Ru} / \mathrm{LDH}-\mathrm{GO}-\mathrm{P}$ can be attributed to the following reasons: 1) the $\mathrm{Co}^{3+}$ centers in $\mathrm{Ru} / \mathrm{LDH}-\mathrm{GO}-\mathrm{P}$ can promote the formation of surface oxygen vacancies that can adsorb and activate $\mathrm{O}_{2}$ to get better performance; 2) the Ru/LDH-GO-P exhibited larger BET surface and more medium-strong basic active sites than the Ru/LDH-GO-V. Moreover, the $\mathrm{Ru} / \mathrm{LDH}-\mathrm{GO}-\mathrm{P}$ catalyst can be easily recovered from the reaction system and reused for at least five times without obvious deterioration of its catalytic activity or structural integrity.
\end{abstract}




\section{Introduction}

In recent years, the cascade reaction systems have attracted wide attention since it can improve efficiency of chemical processes and reduce the waste production. ${ }^{[1]}$ As a result, rational design of catalysts with well-defined and spatially isolated multiple active sites plays a significant role in the optimization of cascade reaction systems. Since many of the employed homogeneous catalytic systems are known to suffer from separation issues from the reaction medium, ${ }^{[2]}$ research efforts mainly focus on the development of heterogeneous systems such as UiO-66-Ru, ${ }^{[3]} \mathrm{NH}_{2}-\mathrm{MIL}-101,{ }^{[4]} \mathrm{Au} @ \mathrm{Cu}(\mathrm{II})-\mathrm{MOF},{ }^{[5]}$ Tris-LDH-Zn $4\left(\mathrm{PW}_{9}\right)_{2},{ }^{[6]}$ $\mathrm{Pd} / \mathrm{COF}-\mathrm{TpPa}-\mathrm{Py},{ }^{[7]}$ and $\mathrm{Ni}_{3} \mathrm{Ga}-\mathrm{LDH},{ }^{[8]}$ which have demonstrated good catalytic activity in one-pot cascade reactions. Although these catalysts were efficient for the cascade reactions, they are largely restricted by the facts such as the requirement of excessive amounts of oxygen donor reagents, the addition of soluble base, and the use of high temperature. As such, the development of effective catalytic systems tailored for cascade reactions under mild conditions is highly desirable and challenging.

Layered double hydroxides (LDHs) are composed of brucite-like two-dimensional sheets and interlayer anions with general chemical formula $\left[\mathrm{M}^{2+}{ }_{1-\mathrm{x}} \mathrm{M}^{3+}{ }_{\mathrm{x}}(\mathrm{OH})_{2}\right]^{\mathrm{x}+}\left[\mathrm{A}_{\mathrm{x} / \mathrm{n}}\right]^{\mathrm{n}-\cdot} \cdot m \mathrm{H}_{2} \mathrm{O},{ }^{[9]}$ where $\mathrm{M}^{2+}$ and $\mathrm{M}^{3+}$ represent di- and trivalent metal cations, $\mathrm{A}^{\mathrm{n}-}$ is the counterion. ${ }^{[10]}$ Due to fascinating properties that can be finely tuned by appropriate choice of the metal ions and guest anions, ${ }^{[11]}$ LDHs have been widely used in various fields. ${ }^{[12]}$ In addition, LDHs can efficiently catalyze Knoevenagel condensation reactions owing to the presence of abundant and accessible hydroxyl groups. ${ }^{[13,6]}$ LDH materials ensure immobilization and high dispersion of metal particles due to its excellent adsorption capacity within the gallery of the LDH. ${ }^{[14]}$ Previously reported examples of LDH-supported catalysts, such as the Ru-LDH, ${ }^{[15]}$ $\mathrm{Pd}-\mathrm{LDH},{ }^{[16]} \mathrm{Au}-\mathrm{LDH}^{[17]}$ showed significantly higher catalytic activity than those immobilized on other supports.

Graphene oxides (GO) exhibits a two-dimensional honeycomb $\mathrm{sp}^{2}$ carbon lattice with extremely large surface area and fast electron transfer properties due to its high conductivity. ${ }^{[18]}$ However, the graphene-based materials tend to stack together due to $\pi-\pi$ interactions, largely limiting their application. Thus, GO's physical and chemical properties 
renders it an excellent support system for the immobilization of catalysts and development of composite nanomaterials with superior functionality. Immobilization of LDH nanosheets on the surface of GO, exhibits the following advantages: 1) the presence of the LDH and interaction with the GO's nanosheets can decrease the $\pi-\pi$ interactions and prevent their aggregation; ${ }^{[19]} 2$ ) the large specific surface area of GO disperses effectively the LDH's active sites. $^{[20]}$

In this work, we reported the preparation and characterization of two bifunctional catalysts Ru/LDH-GO-P and Ru/LDH-GO-V by in-situ synthesis and immobilization of LDH on GO surface by single-drop method and co-precipitation method, respectively. Investigation of their catalytic efficiency in one-pot oxidation-Knoevenagel condensation reaction under the same experimental conditions revealed significant differences between the two catalytic systems which greatly depends on the morphology of the composite. The $\mathrm{Ru} / \mathrm{LDH}-\mathrm{GO}-\mathrm{P}$ exhibited much better activity and selectivity in the cascade reaction between cinnamyl alcohol and ethyl cyanoacetate to produce cinnamylidene ethyl cyanoacetate under mild conditions. Moreover, the heterogeneous catalyst of Ru/LDH-GO-P can be easily recovered and reused for at least five times without obvious deterioration of their structural integrity and activity.

\section{Experimental Section}

All chemicals were of analytical grade and were used as received without any further purification. $\mathrm{RuCl}_{3} \cdot 3 \mathrm{H}_{2} \mathrm{O}, \mathrm{CoCl}_{2} \cdot 6 \mathrm{H}_{2} \mathrm{O}, \mathrm{AlCl}_{3} \cdot 6 \mathrm{H}_{2} \mathrm{O}, \mathrm{NaOH}$, and $\mathrm{Na}_{2} \mathrm{CO}_{3}$, were obtained from Energy Chemical in Shanghai. Ethyl cyanoacetate (98\%), malononitrile (97\%), cinnamyl alcohol (98\%) and other alcohols were purchased from Alfa Aesar. Graphite was purchased from Chengdu Organic Chemicals Co. Ltd, Chinese Academy of Sciences.

Powder XRD patterns were recorded on a Rigaku XRD-6000 diffractometer under the following conditions: $40 \mathrm{kV}, 30 \mathrm{~mA}, \mathrm{Cu}_{\mathrm{K} \alpha}$ radiation $(1=0.154 \mathrm{~nm})$. FT-IR spectra were recorded on a Bruker Vector 22 infrared spectrometer using $\mathrm{KBr}$ pellets. Diffuse reflectance Fourier transform infrared (DRIFT) spectra were recorded on a Bruker Tensor 27 spectrometer. Raman measurements were recorded on a Renishaw Raman spectrometer using a laser excitation wavelength of $532 \mathrm{~nm}$. The $\mathrm{N}_{2}$ adsorption-desorption isotherms were 
measured on a Quantachrome Autosorb-1 system at the liquid-nitrogen temperature, and the samples were degassed at $120^{\circ} \mathrm{C}$ for $6 \mathrm{~h}$ before the measurements. TG-DTA was performed on a TGA/DSC 1/1100 SF from Mettler Toledo in flowing $\mathrm{N}_{2}$ with a heating rate of 10 ${ }^{\circ} \mathrm{C} / \mathrm{min}$ from $33{ }^{\circ} \mathrm{C}$ to $900{ }^{\circ} \mathrm{C}$. XPS measurements were performed on a PHI Quantera SXM using monochromatized $\mathrm{Al}_{\mathrm{K} \alpha}$ exciting $\mathrm{X}$-radiation. Temperature-programmed desorption (TPD) was probed by using a PCA-1200 Chemical adsorption apparatus 1100 analyzer equipped with a thermal conductivity detector (TCD). The ${ }^{1} \mathrm{H}-\mathrm{NMR}$ spectra were recorded on a Bruker AV400 NMR spectrometer at resonance frequency of $400 \mathrm{MHz}$, and the chemical shifts were given relative to TMS as the internal reference. The K-edge XANES measurements were performed at the 1W1B beamline of Beijing Synchrotron Radiation Facility. Fourier transform EXAFS (FT-EXAFS) shell fitting was carried out with Artemis Software.

The transition metal stock solution: In a typical experiment, the transition metal stock solution was prepared by mixing $\mathrm{RuCl}_{3} \cdot 3 \mathrm{H}_{2} \mathrm{O}(98.05 \mathrm{mg}, 0.375 \mathrm{mmol}), \mathrm{CoCl}_{2} \cdot 6 \mathrm{H}_{2} \mathrm{O}(892.24$ $\mathrm{mg}, 3.75 \mathrm{mmol})$ and $\mathrm{AlCl}_{3} \cdot 6 \mathrm{H}_{2} \mathrm{O}(301.79 \mathrm{mg}, 1.25 \mathrm{mmol})$ in distilled water $(25 \mathrm{~mL})$.

The alkali metal stock solution: it was prepared by mixing $\mathrm{Na}_{2} \mathrm{CO}_{3}(530 \mathrm{mg}, 2.5 \mathrm{mmol})$ and $\mathrm{NaOH}(800 \mathrm{mg}, 10 \mathrm{mmol})$ in $50 \mathrm{~mL}$ of distilled water.

Synthesis of Ru/LDH-sd: This compound was prepared using single-drop method as following. The alkali metal stock solution was added dropwise into the transition metal stock solution with vigorous stirring at room temperature until $\mathrm{pH}=10.0$. The resulting suspension was aged at $363 \mathrm{~K}$ for $6 \mathrm{~h}$. After that, the solution was filtered and the precipitate was washed with deionized water $(3 \times 20 \mathrm{~mL})$. The obtained solid sample was dried at $333 \mathrm{~K}$ overnight under vacuum to obtain $\mathrm{Ru} / \mathrm{CoAl}-\mathrm{LDH}(\mathrm{Ru} / \mathrm{LDH}-\mathrm{sd})$.

Synthesis of Ru/LDH-cp: This compound was prepared using co-precipitation method. The transition metal stock solution and the alkali metal solution were added dropwise simultaneously into the $25 \mathrm{~mL}$ distilled water with vigorous stirring at room temperature and the $\mathrm{pH}$ of the mixture was controlled to 10.0. Then, the resulting suspension was aged at 363 $\mathrm{K}$ for $6 \mathrm{~h}$. After that, the mixture was filtered and the resultant precipitate was washed with deionized water $(3 \times 20 \mathrm{~mL})$. The obtained solid was dried at $333 \mathrm{~K}$ overnight in a vacuum oven to obtain $\mathrm{Ru} / \mathrm{CoAl}-\mathrm{LDH}(\mathrm{Ru} / \mathrm{LDH}-\mathrm{cp})$. 
GO was synthesized and characterized according to previously reported method. ${ }^{[21]}$

Synthesis of Ru/LDH-GO-P: The transition metal stock solution was added into the GO suspension and the mixture was sonicated for $30 \mathrm{~min}$, to which the alkali metal stock solution was added dropwise with vigorous stirring at room temperature until $\mathrm{pH}=10.0$. The resulting suspension was aged at $363 \mathrm{~K}$ for $6 \mathrm{~h}$, and the mixture was filtered and the precipitate was washed with deionized water $(3 \times 20 \mathrm{~mL})$. The obtained solid sample was dried at $333 \mathrm{~K}$ overnight under vacuum, and it was denoted as $\mathrm{Ru} / \mathrm{LDH}-\mathrm{GO}-\mathrm{P}$ due to the presence of LDH in parallel growth on the GO.

Synthesis of Ru/LDH-GO-V: The transition metal stock solution and the alkali metal solution were added simultaneously dropwise into the GO suspension with vigorous stirring at room temperature, and the $\mathrm{pH}$ of the solution was controlled to 10.0. The resulting suspension was aged at $363 \mathrm{~K}$ for $6 \mathrm{~h}$. After that, the mixture was filtered and the precipitate was washed with deionized water $(3 \times 20 \mathrm{~mL})$. The obtained solid was dried at $333 \mathrm{~K}$ overnight in a vacuum, and it was denoted as $\mathrm{Ru} / \mathrm{LDH}-\mathrm{GO}-\mathrm{V}$ because the $\mathrm{LDH}$ was grown vertically on GO.

\section{Catalytic test}

In a typical One-pot oxidation-Knoevenagel condensation reaction, solid catalyst (100 $\mathrm{mg})$, benzyl alcohol $(1 \mathrm{mmol})$ and toluene $(7 \mathrm{~mL})$ were mixed in a $50 \mathrm{~mL}$ three-necked flask. The reaction mixture was kept under stirring at $333 \mathrm{~K}$ under $\mathrm{O}_{2}$ bubble $(10 \mathrm{~mL} / \mathrm{min}$ for 2 hours, $0.10 \mathrm{MPa}$ ). After the reaction progressed for a desired period of time, ethyl cyanoacetate $(1.5 \mathrm{mmol})$ was charged into the reaction system rapidly. The mixture was left at $333 \mathrm{~K}$ for an additional time period. The resulting products were extracted with $\mathrm{CH}_{2} \mathrm{Cl}_{2}$ and analyzed by gas chromatography equipped with a flame ionization detector (GC-FID). The yields were calculated by using reference standards. The obtained products (purified by rotary evaporation and silica gel column chromatography eluted with petroleum ether/EtOAc $=5: 1)$ were dissolved in $\mathrm{CDCl}_{3}$ and analyzed by ${ }^{1} \mathrm{H}$ NMR spectroscopy. After completion of the reaction, the catalyst was recovered by centrifugation, washed with acetone, and dried under $333 \mathrm{~K}$ overnight. 


\section{Results and Discussion}

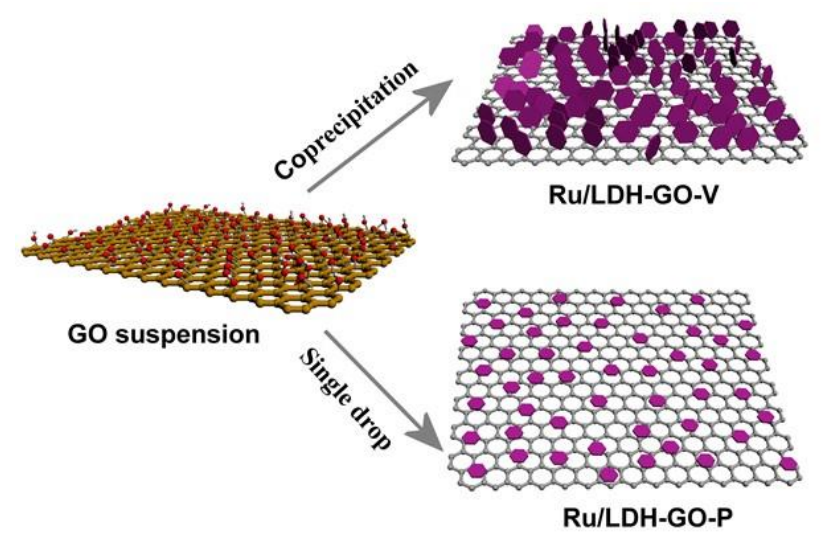

Scheme 1. Schematic representation of the Ru/LDH-GO-V and Ru/LDH-GO-P nanocomposites.

As shown in Scheme 1, the Ru/LDH-GO-P nanocomposite was synthesized via single drop method, while the $\mathrm{Ru} / \mathrm{LDH}-\mathrm{GO}-\mathrm{V}$ nanocomposite was prepared using co-precipitation method. The $\mathrm{Ru} / \mathrm{LDH}-\mathrm{GO}-\mathrm{P}$ and $\mathrm{Ru} / \mathrm{LDH}-\mathrm{GO}-\mathrm{V}$ revealed rather similar XRD patterns (Figure 1a). The peaks located at $2 \theta=12,24,35,39,60$, and $62^{\circ}$ can be indexed to the (003), (006), (009), (015), (110) and (113) reflection of the LDH phase with 3R symmetry, respectively. ${ }^{[21]}$ The GO present a characteristic $(001)$ diffraction at $2 \theta=11.9^{\circ}$, indicative of an interlayer distance of approximately $0.74 \mathrm{~nm},{ }^{[19]}$ which can be attributed to the formation of oxygenated functional groups on the graphite layers. No typical diffraction peak of GO was observed in the corresponding nanocomposites, which can be attributed to the superimposed reflections with LDH. ${ }^{[22]}$

As shown in Figure 1b, Raman spectrum of GO revealed the G band at $1598 \mathrm{~cm}^{-1}$ and the $\mathrm{D}$ band at $1342 \mathrm{~cm}^{-1}$, respectively. ${ }^{[23]}$ The intensity ratio of the $\mathrm{D}$ to the $\mathrm{G}$ band $\left(I_{D} / I_{G}\right)$ provides the surface defect and the degree of lattice distortion of the graphite layer within the carbon material. The gradual increase of the $I_{D} / I_{G}$ ratio from 0.92 for $\mathrm{GO}$, to 0.96 for $\mathrm{Ru} / \mathrm{LDH}-\mathrm{GO}-\mathrm{V}$ and 1.04 for Ru/LDH-GO-P (Table S1) was indicative of the effective immobilization of the $\mathrm{LDH}$ on the GO surface. The higher $I_{D} / I_{G}$ value resulted in the conjugated carbon atoms with more structural defects. ${ }^{[2]}$ The increased number of defect sites on the surface of graphene may play an important role in promoting the in-situ formation and immobilization of $\mathrm{LDH}$ on $\mathrm{GO}$, which is important for the inhibition of the agglomeration of LDH nanosheets during the growth process and consequently the high 
dispersion of $\mathrm{Ru}$ active centers.
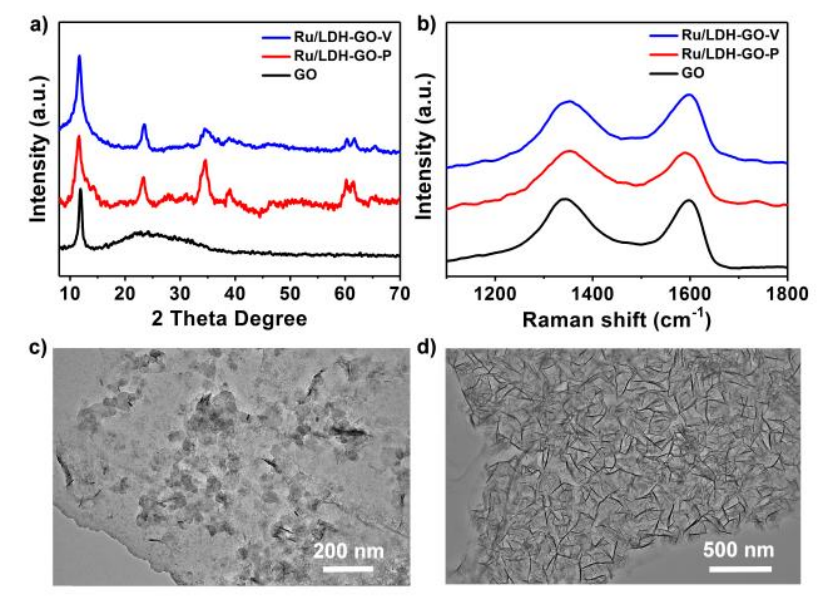

Figure 1. a) XRD patterns of GO, Ru/LDH-GO-P, and Ru/LDH-GO-V. b) Raman spectra of GO, Ru/LDHGO-P, and Ru/LDH-GO-V. c) TEM image of Ru/LDH-GO-P. d) TEM image of Ru/LDH-GO-V.

Interestingly, TEM and SEM images of Ru/LDH-GO-P (Figure 1c, S1, S2) exhibited dramatic difference from those of Ru/LDH-GO-V (Figure 1d, S1, S2). In the case of $\mathrm{Ru} / \mathrm{LDH}-\mathrm{GO}-\mathrm{P}$, the LDHs grew with ab-planes of the crystallites oriented parallel to GO (Figure S3), whereas for $\mathrm{Ru} / \mathrm{LDH}-\mathrm{GO}-\mathrm{V}$, the ab-planes can be found to be oriented perpendicular to GO. Such morphological difference can be assigned to be the different concentration of LDH nucleation points formed in the synthetic process. ${ }^{[24]}$ In the case of $\mathrm{Ru} / \mathrm{LDH}-\mathrm{GO}-\mathrm{V}$, high concentration of LDH nucleation points were formed by simultaneous addition of alkali and transition metal stock solution into the GO dispersion, according to the co-precipitation method. Thus, the high concentration of LDH led to the growth and subsequent immobilization of LDH crystallites with their ab-planes aligned perpendicular to the GO substrate. However, in the case of Ru/LDH-GO-P which was formed using single drop method, the transition metal stock solution and the GO dispersion were mixed before the subsequent addition of the alkali solution. As a result, the local concentration of LDH nucleation points on the surface of GO was much lower than in the case of co-precipitation method. Low local concentrations promoted slower generation of nucleation points on the GO surface and the LDH crystallites were oriented with their ab-faces parallel to the GO film. FT-IR spectrum (Figure S4) of GO itself showed the peaks at 1722, 1624, $1058 \mathrm{~cm}^{-1}$ that can be assigned to the $\mathrm{C}=\mathrm{O}$ stretching bands of $\mathrm{COOH}$ groups, the carbon backbone $(\mathrm{C}=\mathrm{C} / \mathrm{C}-\mathrm{C})$, and the alkoxy $(\mathrm{C}-\mathrm{O})$, respectively. ${ }^{\left[{ }^{[2]}\right.}$ In contrast, these bands disappeared in the 
corresponding FT-IR spectrum of Ru/LDH-GO-P and Ru/LDH-GO-V, which was indicative of partial reduction of the GO during the formation of LDH-GO composite. ${ }^{[26]}$
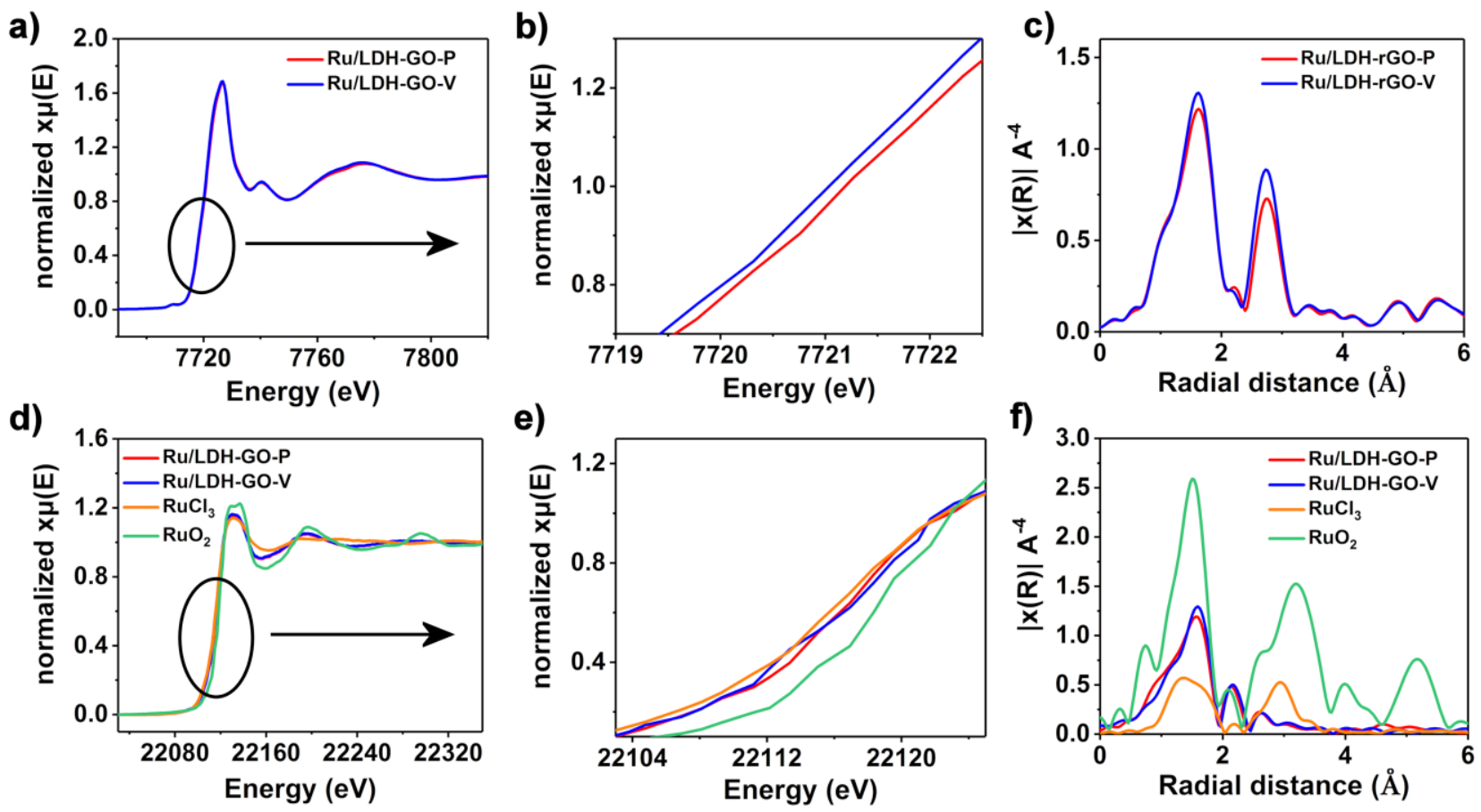

Figure 2. a) Normalized Co K-edge XANES spectra of Ru/LDH-GO-P, and Ru/LDH-GO-V. b) Locally amplified version of Normalized Co K-edge XANES spectra. c) The $\mathrm{k}^{3}$-weighted Fourier transform spectra from Co K edge EXAFS. d) Normalized Ru K-edge XANES spectra of Ru/LDH-GO-P, Ru/LDH-GO-V, $\mathrm{RuCl}_{3}$, and $\mathrm{RuO}_{2}$. e) Locally amplified version of Normalized Ru K-edge XANES spectra. f) The $\mathrm{k}^{3}$-weighted Fourier transform spectra from Ru K edge EXAFS.

Subsequently, we utilized X-ray absorption spectroscopy (XAS) in an effort to elucidate the chemical state and coordination environment of $\mathrm{Co}$ and $\mathrm{Ru}$ atoms. The Co K-edge X-ray absorption near edge structure (XANES) spectra (Figure 2a-2b, S5a) suggested that the valence state of $\mathrm{Co}$ in $\mathrm{Ru} / \mathrm{LDH}-\mathrm{GO}-\mathrm{P}$ was higher than that in $\mathrm{Ru} / \mathrm{LDH}-\mathrm{GO}-\mathrm{V}$. The corresponding Fourier Transformed (FT) $\mathrm{k}^{3} \chi(\mathrm{k})$ functions (Figure 2c) showed that both $\mathrm{Ru} / \mathrm{LDH}-\mathrm{GO}-\mathrm{P}$ and $\mathrm{Ru} / \mathrm{LDH}-\mathrm{GO}-\mathrm{V}$ exhibited two prominent peaks at 1.6 and $2.8 \AA$, corresponding to the nearest $\mathrm{Co}-\mathrm{O}_{\mathrm{OH}}$ and the neighboring $\mathrm{Co}-\mathrm{Co}$ coordination, respectively. The peak intensity for $\mathrm{Co}-\mathrm{O} O \mathrm{OH}$ and $\mathrm{Co}-\mathrm{Co}$ coordination in $\mathrm{Ru} / \mathrm{LDH}-\mathrm{GO}-\mathrm{P}$ were significantly lower than the corresponding peaks in $\mathrm{Ru} / \mathrm{LDH}-\mathrm{GO}-\mathrm{V}$, suggesting that the Ru/LDH-GO-P possessed more $\mathrm{Co}$ and $\mathrm{O}$ vacancies than the $\mathrm{Ru} / \mathrm{LDH}-\mathrm{GO}-\mathrm{V}$. As shown in Figure 2e and $\mathrm{S} 5 \mathrm{~b}$, the $\mathrm{Ru} \mathrm{K}$-edge for both nanocomposites is close to that of the $\mathrm{RuCl}_{3}$ reference, 
suggesting that the oxidation state of $\mathrm{Ru}$ remained +3 . As can be seen from the EXAFS spectrum in $\mathrm{R}$ space (Figure $2 \mathrm{f}$ ), the $\mathrm{Ru} / \mathrm{LDH}-\mathrm{GO}-\mathrm{P}$ and $\mathrm{Ru} / \mathrm{LDH}-\mathrm{GO}-\mathrm{V}$ exhibited a prominent peak at approximately $1.6 \AA$ from the $\mathrm{Ru}-\mathrm{O}$ shell. No other typical peaks for $\mathrm{Ru}-$ $\mathrm{Ru}$ contributions at longer distances $(>2.0 \AA)$ were observed, indicating the high dispersion of isolated $\mathrm{Ru}^{3+}$ through the $\mathrm{Ru} / \mathrm{LDH}-\mathrm{GO}$ nanosheets. ${ }^{[27]}$
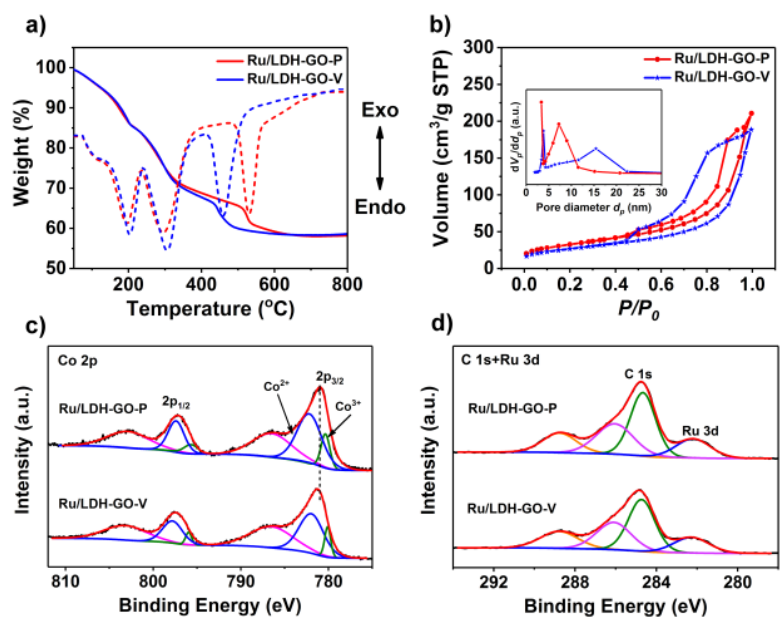

Figure 3. a) TG-DTA profile of Ru/LDH-GO-P and Ru/LDH-GO-V. b) The $\mathrm{N}_{2}$ adsorption-desorption isotherm and the pore size distribution (inset picture) of Ru/LDH-GO-P and Ru/LDH-GO-V. c) Co 2p XPS spectra for Ru/LDH-GO-P, Ru/LDH-GO-V. d) C 1s+Ru 3d XPS spectra for Ru/LDH-GO-P, Ru/LDH-GO-V.

Thermogravimetric and differential thermal analysis (TG-DTA) of Ru/LDH-GO-P and $\mathrm{Ru} / \mathrm{LDH}-\mathrm{GO}-\mathrm{V}$ showed three distinct stages of weight loss upon temperature increase from 30 to $800{ }^{\circ} \mathrm{C}$ (Figure 3a). In the case of $\mathrm{Ru} / \mathrm{LDH}-\mathrm{GO}-\mathrm{P}$, the first weight loss of $15.21 \%$ took place between 30 and $220^{\circ} \mathrm{C}$ that can be ascribed to the removal of water molecules absorbed on the surface and the interlayer space. The second weight loss of $17.33 \%$ between 220 and $440{ }^{\circ} \mathrm{C}$ corresponded to the subsequent disintegration of the layered structure. The third weight loss of $9.29 \%$ between 440 and $630{ }^{\circ} \mathrm{C}$ was related to the combustion of the carbon skeleton. ${ }^{[28]}$ In case of Ru/LDH-GO-V, the first two weight losses were similar to the ones observed in $\mathrm{Ru} / \mathrm{LDH}-\mathrm{GO}-\mathrm{V}$. However, the third weight loss temperature took place at slightly lower temperatures (between 390 and $560{ }^{\circ} \mathrm{C}$ ), which was due to the weaker interactions between the LDH and GO. To further investigate the possibility of a porous structure and to determine the surface area of the prepared composites, the $\mathrm{N}_{2}$ adsorption-desorption isotherm and the Barrett-Joyner-Halenda $(\mathrm{BJH})$ pore size distribution plots of Ru/LDH-GO-V, $\mathrm{Ru} / \mathrm{LDH}-\mathrm{GO}-\mathrm{P}$ and GO were calculated (Figure 3b, S6). All samples exhibited typical type 
IV adsorption isotherms and $\mathrm{H} 3$ type hysteresis loops at a high relative pressure $\left(\mathrm{P} / \mathrm{P}_{0}>0.4\right)$, which indicates the predominant presence of mesopores. Ru/LDH-GO-P showed a peak centered at approximately $3.8 \mathrm{~nm}$ (Figure 3b, inset) and $\mathrm{Ru} / \mathrm{LDH}-\mathrm{GO}-\mathrm{V}$ showed a peak centered at approximately $3.3 \mathrm{~nm}$. The larger surface area of Ru/LDH-GO-P $\left(116.49 \mathrm{~m}^{2} \cdot \mathrm{g}^{-1}\right)$ than that of $\mathrm{Ru} / \mathrm{LDH}-\mathrm{GO}-\mathrm{V}\left(94.62 \mathrm{~m}^{2} \cdot \mathrm{g}^{-1}\right)$ may have a profound effect on the adsorption of $\mathrm{O}_{2}$ and subsequent efficiency during the catalytic processes.

XPS spectra of the Co2p, Ru3d, C1s, Ru3p, A12p and O1s were presented in Figure 3, S7. The Co2p core lines of the Ru/LDH-GO-P and Ru/LDH-GO-V (Figure 3c) can be split into $\mathrm{Co} 2 \mathrm{p}_{3 / 2}(\sim 781.1 \mathrm{eV})$ and Co $2 \mathrm{p}_{1 / 2}(\sim 797.3 \mathrm{eV})$ peaks along with two satellite bands located at 786.6 and $803.4 \mathrm{eV}$, indicating the existence of high-spin $\mathrm{Co}^{2+}$ state in both cases. ${ }^{[29]}$ It was worth noting that the binding energies of Co2 $p_{3 / 2}$ and Co2 $p_{1 / 2}$ in $\mathrm{Ru} / \mathrm{LDH}$ GO-P (781.0 and $797.1 \mathrm{eV})$ are both $\sim 0.3 \mathrm{eV}$ lower than those in Ru/LDH-GO-V (781.3 and $797.4 \mathrm{eV}$ ), confirming the enhanced electron density of Co atoms, which is consistent with the XAFS data. ${ }^{[30]}$ The atomic ratios of $\mathrm{Co}^{3+} / \mathrm{Co}^{2+}$ in $\mathrm{Ru} / \mathrm{LDH}-\mathrm{GO}-\mathrm{P}$ and $\mathrm{Ru} / \mathrm{LDH}-\mathrm{GO}-\mathrm{V}$ were found to be 0.22 and 0.16 , respectively. This result indicated the presence of more $\mathrm{Co}^{3+}$ centers in $\mathrm{Ru} / \mathrm{LDH}-\mathrm{GO}-\mathrm{P}$ that can promote the formation of surface oxygen vacancies that can adsorb and activate $\mathrm{O}_{2} \cdot{ }^{[15,31]}$ As shown in Figure $3 \mathrm{~b}$, deconvolution of both $\mathrm{Ru} 3 \mathrm{~d}_{5 / 2}$ profiles of $\mathrm{Ru} / \mathrm{LDH}-\mathrm{GO}-\mathrm{P}$ and $\mathrm{Ru} / \mathrm{LDH}-\mathrm{GO}-\mathrm{V}$ showed the main binding energy peak at $282.1 \mathrm{eV}$, which can be attributed to $\mathrm{Ru}(\mathrm{OH})_{3} .^{[32]}$

Table 1. Performance of different catalysts in the oxidation of cinnamyl alcohol and the subsequent Knoevenagel condensation with ethyl cyanoacetate. ${ }^{[a]}$

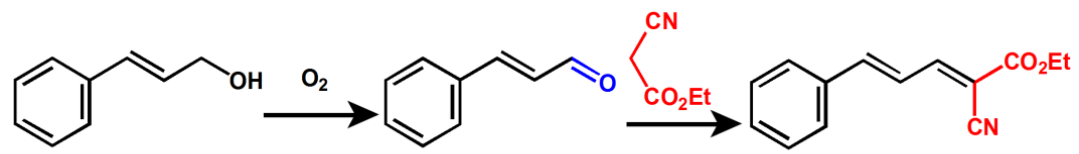

A $\quad$ B C

\begin{tabular}{ccccc}
\hline Entry & Catalyst & Conv. A (\%) & Yield B (\%) & Yield C (\%) \\
\hline 1 & Ru/LDH-GO-P & $>99$ & 0 & 99 \\
2 & Ru/LDH-GO-V & 60.7 & 12.8 & 47.9 \\
3 & Ru/LDH-sd & 40.9 & 10.6 & 30.3 \\
4 & $\mathrm{Ru} / \mathrm{LDH}-\mathrm{cp}$ & 21.5 & 7.9 & 13.6 \\
$5^{[\mathrm{b}]}$ & $\mathrm{RuCl}_{3}$ & 0 & 0 & 0 \\
$6^{[\mathrm{c}]}$ & $\mathrm{GO}$ & 0 & 0 & 0
\end{tabular}




\begin{tabular}{ccccc}
$7^{[\mathrm{d}]}$ & $\mathrm{RuCl}_{3}+\mathrm{LDH}-\mathrm{sd}+\mathrm{GO}$ & 43.5 & 9.5 & 36.0 \\
$8^{[\mathrm{e}]}$ & $\mathrm{RuCl}_{3}+\mathrm{LDH}-\mathrm{cp}+\mathrm{GO}$ & 22.0 & 7.5 & 14.5 \\
9 & No catalyst & 0 & 0 & 0 \\
\hline${ }^{[\mathrm{a}]}$ Reaction conditions: catalyst $(100 \mathrm{mg}), \mathrm{A}(1 \mathrm{mmol})$, ethyl cyanoacetate $(1.5 \mathrm{mmol}), \mathrm{O}_{2}$, \\
solvent $(7 \mathrm{~mL}), \mathrm{T}=333 \mathrm{~K}, 3 \mathrm{~h} .{ }^{[\mathrm{b}]} \mathrm{RuCl}_{3}(19.6 \mathrm{mg}),{ }^{[\mathrm{c}]} \mathrm{GO}(10 \mathrm{mg}) .{ }^{[\mathrm{d}]} \mathrm{RuCl}_{3}(19.6 \mathrm{mg})$, \\
LDH-sd $(80.4 \mathrm{mg}), \mathrm{GO}(10 \mathrm{mg}) .{ }^{[\mathrm{e}]} \mathrm{RuCl}_{3}(19.6 \mathrm{mg}), \mathrm{LDH}-\mathrm{cp}(80.4 \mathrm{mg}), \mathrm{GO}(10 \mathrm{mg})$
\end{tabular}

The catalytic activity of Ru/LDH-GO-P, and Ru/LDH-GO-V in the one-pot tandem synthesis of cinnamylidene ethyl cyanoacetate (abbreviated as C) from cinnamyl alcohol (denoted as A) was investigated in toluene under oxygen atmosphere. The results were summarized in Table 1. The one-pot synthesis of cinnamylidene ethyl cyanoacetate was realized through the oxidation of cinnamyl alcohol followed by Knoevenagel condensation with ethyl cyanoacetate. Cinnamyl aldehyde (denoted as B) was produced as an intermediate in all cases. The cascade reaction proceeded smoothly with $99 \%$ conversion and $99 \%$ selectivity of cinnamylidene ethyl cyanoacetate using Ru/LDH-GO-P as catalyst (Table 1, entry 1 ). In contrast, $\mathrm{Ru} / \mathrm{LDH}-\mathrm{GO}-\mathrm{V}$ did not promote the reaction as efficiently as $\mathrm{Ru} / \mathrm{LDH}-$ GO-P with the conversion of $47.9 \%$ (entry 2). Moreover, the control experiments using $\mathrm{Ru} / \mathrm{LDH}$-sd and $\mathrm{Ru} / \mathrm{LDH}-\mathrm{cp}$ as catalysts showed considerably lower conversion of A (entries $3,4)$, indicating that the introduction of GO can decrease the $\pi-\pi$ interactions and aggregation of $\mathrm{LDH}$ nanosheets and facilitate the dispersion of active sites. Bare $\mathrm{GO}$ and $\mathrm{RuCl}_{3}$ also showed no activity for the cascade reaction. Finally, the physical mixture of GO and LDH showed inferior efficiency (entries 6,7 ) since both activity and selectivity were considerably lower than those using $\mathrm{Ru} / \mathrm{LDH}-\mathrm{GO}-\mathrm{P}$ as catalyst.

The $\mathrm{CO}_{2}$-TPD measurements were performed in order to obtain information about the number of basic sites present on the solids. As shown in Figure 4a, the broad peak for $\mathrm{CO}_{2}$ desorption between 100 and $200{ }^{\circ} \mathrm{C}$ can be deconvoluted into two contributions in the range of $100-170{ }^{\circ} \mathrm{C}$ and $170-200{ }^{\circ} \mathrm{C}$, which were identified as weak and medium-strong basic sites, respectively. ${ }^{[33]}$ Moreover, the $\mathrm{Ru} / \mathrm{LDH}-\mathrm{GO}-\mathrm{P}$ showed substantially more (weak and medium-strong) basic sites than $\mathrm{Ru} / \mathrm{LDH}-\mathrm{GO}-\mathrm{V}$, which was consistent with the fact that the $\mathrm{Ru} / \mathrm{LDH}-\mathrm{GO}-\mathrm{P}$ performed more efficiently than the Ru/LDH-GO-V for the above cascade reaction. 

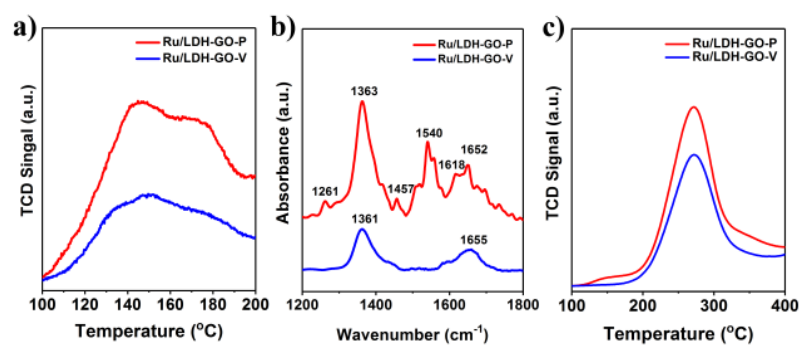

Figure 4. a) $\mathrm{CO}_{2}$-TPD of $\mathrm{Ru} / \mathrm{LDH}-\mathrm{GO}-\mathrm{P}$ and $\mathrm{Ru} / \mathrm{LDH}-\mathrm{GO}-\mathrm{V}$, b) in situ $\mathrm{CO}_{2}-\mathrm{IR}$ of Ru/LDH-GO-P and $\mathrm{Ru} / \mathrm{LDH}-\mathrm{GO}-\mathrm{V}$, c) $\mathrm{O}_{2}$-TPD of Ru/LDH-GO-P and Ru/LDH-GO-V.

In order to demonstrate further the difference between the basic sites of the two catalysts, we employed the in-situ $\mathrm{CO}_{2}$-IR technique (Figure 4b). Three species of adsorbed $\mathrm{CO}_{2}$ were detected, which can be assigned to bicarbonates, bidentate carbonates, and monodentate carbonates (Table S2). This result confirmed the presence of three different types of surface basic sites. Bicarbonates were formed from the interaction of $\mathrm{CO}_{2}$ with $\mathrm{OH}$ groups, while bidentate carbonates and monodentate carbonates can be originated from the interaction of $\mathrm{CO}_{2}$ with $\mathrm{M}-\mathrm{O}$ ion pairs and surface $\mathrm{O}^{2-}$ ions, respectively. ${ }^{[30,34]}$ The IR spectrum of $\mathrm{Ru} / \mathrm{LDH}-\mathrm{GO}-\mathrm{P}$ was noticeably more complex than that of Ru/LDH-GO-V. For Ru/LDH-GO$\mathrm{P}$, the characteristic peak of bidentate carbonates at $1618 \mathrm{~cm}^{-1}$ indicated the presence of $\mathrm{M}-\mathrm{O}$ ion pairs than that in $\mathrm{Ru} / \mathrm{LDH}-\mathrm{GO}-\mathrm{V}$, which was consistent with the $\mathrm{CO}_{2}$-TPD studies. To examine the mobility of oxygen species, we conducted $\mathrm{O}_{2}$-TPD tests. For both $\mathrm{Ru} / \mathrm{LDH}-\mathrm{GO}-$ $\mathrm{P}$ and $\mathrm{Ru} / \mathrm{LDH}-\mathrm{GO}-\mathrm{V}$, the broad peaks located in the range of 150 and $350{ }^{\circ} \mathrm{C}$ were assigned to the chemisorbed oxygen $\mathrm{O}_{2}{ }^{2-}$ and surface-active oxygen species $\mathrm{O}_{2}{ }^{-}$, respectively. ${ }^{[30,35]}$ In addition, the peaks in $\mathrm{Ru} / \mathrm{LDH}-\mathrm{GO}-\mathrm{P}$ showed higher intensity than that in Ru/LDH-GO-V, indicating higher abundance of $\mathrm{O}_{2}{ }^{2-}$ and $\mathrm{O}_{2}{ }^{-}$species.

\section{Kinetic study of cascade oxidation-Knoevenagel condensation reaction}
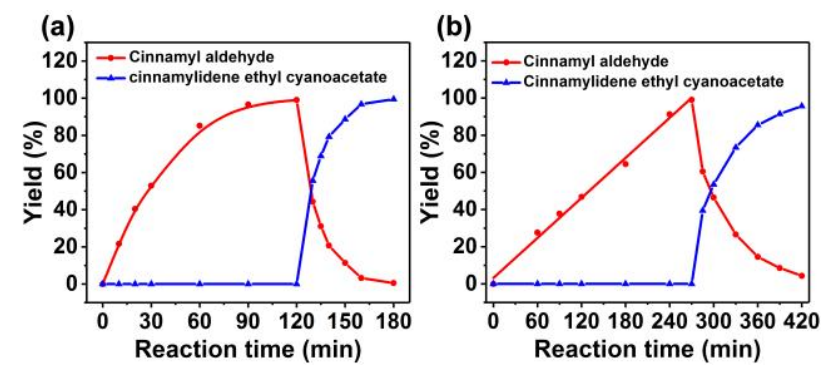
Figure 5. Yields vs reaction time of cinnamyl aldehyde and cinnamylidene ethyl cyanoacetate using a) $\mathrm{Ru} / \mathrm{LDH}-\mathrm{GO}-\mathrm{P}$ and b) Ru/LDH-GO-V as catalysts, respectively.

To describe directly the different reaction pathway between $\mathrm{Ru} / \mathrm{LDH}-\mathrm{GO}-\mathrm{P}$ and $\mathrm{Ru} / \mathrm{LDH}-\mathrm{GO}-\mathrm{V}$, the tandem synthesis of cinnamylidene ethyl cyanoacetate (denoted as $\mathbf{C}$ ) from cinnamyl alcohol (denoted as $\mathbf{A}$ ) was performed at different reaction times. When $\mathrm{Ru} / \mathrm{LDH}-\mathrm{GO}-\mathrm{P}$ was used as catalyst (Figure 5a, S8), the product cinnamyl aldehyde (denoted as B) yield gradually increased to reach maximum within $120 \mathrm{~min}$. Subsequent addition of ethyl cyanoacetate into the reaction mixture led to a rapid decrease of the intermediate $\mathbf{B}$, whereas the yield of $\mathbf{C}$ increased rapidly within $30 \mathrm{~min}$. In contrast, when $\mathrm{Ru} / \mathrm{LDH}-\mathrm{GO}-\mathrm{V}$ was applied as catalyst (Figure 5b, S8), the observed increase of $\mathbf{B}$ and $\mathbf{C}$ was considerably lower than $\mathrm{Ru} / \mathrm{LDH}-\mathrm{GO}-\mathrm{P}$.

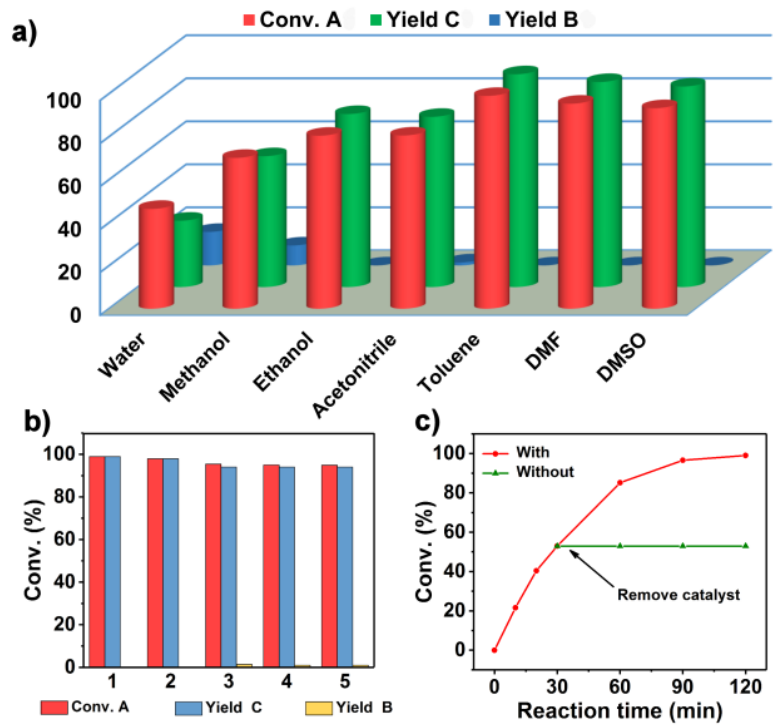

Figure 6. a) Effect of the solvent on the one-pot oxidation-Knoevenagel condensation reaction by $\mathrm{Ru} / \mathrm{LDH}-\mathrm{GO}-\mathrm{P}$. b) Recycling test of the Ru/LDH-GO-P catalyst for 5 times. c) Hot filtration experiments, red line: in the presence of Ru/LDH-GO-P; green line: Ru/LDH-GO-P was filtrated at 30min. Reaction conditions: catalyst $(100 \mathrm{mg}), \mathrm{A}(1 \mathrm{mmol})$, ethyl cyanoacetate $(1.5 \mathrm{mmol}), \mathrm{O}_{2}$, solvent $(7 \mathrm{~mL}), \mathrm{T}=333 \mathrm{~K}, 3$ h.

To identify the best solvent medium for the one-pot oxidation-Knoevenagel condensation reaction, we investigated the effects of a series of solvents on the catalytic efficiency (Figure 6a). The cascade reaction proceeded efficiently with the conversion of $\mathbf{A}$ reaching $95 \%$ in DMSO and 93\% in DMF, respectively. If toluene was used, we observed almost complete conversion of A (99\%) and selectivity of $\mathbf{C}>99 \%$. On the other hand, the catalytic activity 
decreased if water, methanol, ethanol, and acetonitrile were used as solvents in the cascade reaction. Based on the above screening, we selected toluene as the most appropriate solvent medium. As shown in Figure 6b, Ru/LDH-GO-P used for the promotion of the cascade reaction can be easily recovered by filtration and recycled for at least 5 times without obvious deterioration of its catalytic activity. In addition, the characterization of the recycled catalyst using powder XRD and FT-IR (Figure S9) confirmed its structural integrity.

To prove whether the cascade reaction followed heterogeneous or homogeneous pathway, we conducted the following experiment. When the cascade reaction was half-way through (the conversion reached $53 \%$ after $30 \mathrm{~min}$ ), the Ru/LDH-GO-P catalyst was filtered off. And the remaining reaction mixture was kept under the same experimental conditions. As a result, it showed that no additional conversion of the reactant to the product can be observed (Figure 6c). This experiment demonstrates further the efficiency and robustness of the $\mathrm{Ru} / \mathrm{LDH}-\mathrm{GO}-\mathrm{P}$ heterogeneous catalyst.

\section{Comparison with other reported heterogeneous catalysts}

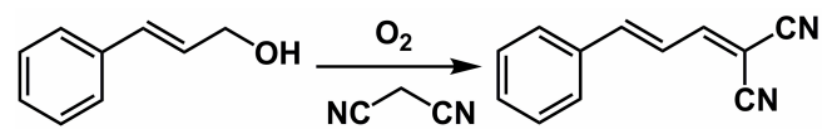

Table 2. Performance of different catalysts in the oxidation of cinnamyl alcohol and the subsequent Knoevenagel condensation with malononitrile.

\begin{tabular}{cccccccc}
\hline Entry & catalyst & oxidant & $\mathbf{T}$ & $\mathbf{t}$ & Conv. [\%] & Yield [\%] & Ref. \\
\hline 1 & $\mathrm{UiO}-66-\mathrm{Ru}(3.6 \mathrm{~mol} \% \mathrm{Ru})$ & $\mathrm{O}_{2}$ & $373 \mathrm{~K}$ & $32 \mathrm{~h}$ & 94.6 & 51.2 & 3 \\
2 & $\mathrm{CuBr}+\mathrm{FL} 2$ & $\mathrm{TEMPO}$ & $313 \mathrm{~K}$ & $13 \mathrm{~h}$ & 66 & - & 36 \\
3 & $\mathrm{Au} / \mathrm{NH}_{2}-\mathrm{UiO}-66$ & $\mathrm{TBHP}$ & $343 \mathrm{~K}$ & $34 \mathrm{~h}$ & 79 & 77 & 37 \\
4 & $30 \% \mathrm{HPW} / \mathrm{mpg}_{-} \mathrm{C}_{3} \mathrm{~N}_{4}$ & $\mathrm{H}_{2} \mathrm{O}_{2}$ & $363 \mathrm{~K}$ & $4 \mathrm{~h}$ & 97.6 & - & 38 \\
5 & $\mathrm{MNP} @ \mathrm{PIL} / \mathrm{W}$ & $\mathrm{H}_{2} \mathrm{O}_{2}$ & $363 \mathrm{~K}$ & $7 \mathrm{~h}$ & 99 & 95 & 39 \\
6 & $\mathrm{Ru} / \mathrm{LDH}-\mathrm{GO}-\mathrm{P}$ & $\mathrm{O}_{2}$ & $333 \mathrm{~K}$ & $2.5 \mathrm{~h}$ & 98.0 & 98.0 & This work \\
\hline
\end{tabular}

The one-pot oxidation-Knoevenagel condensation reactions using a variety of substrates and catalysts reported previously were summarized in Table 2, Table S3 and S4. The $\mathrm{Ru} / \mathrm{LDH}-\mathrm{GO}-\mathrm{P}$ exhibited very good catalytic activity using $\mathrm{O}_{2}$ as oxidant under mild reaction conditions compared with previously reported catalysts. In addition, the Ru/LDH-GO-P 
showed considerably better catalytic activity compared with other noble metal-based catalysts, such as $\mathrm{UiO}-66-\mathrm{Ru}$ and $\mathrm{Au} / \mathrm{NH}_{2}-\mathrm{UiO}-66$ for cinnamyl alcohol and the subsequent Knoevenagel condensation with malononitrile reaction (Table 2, entries 1, 3). Also in the case where the substrate was replaced with benzyl alcohol and malononitrile, Ru/LDH-GO-P still exhibited superior reactivity compared to other reported catalysts (Table S3, entries 2,7,13, Table S4, entries 1, 2, 5). The observed physical and chemical properties (activity, stability and regeneration) renders the $\mathrm{Ru} / \mathrm{LDH}-\mathrm{GO}-\mathrm{P}$ composite catalyst an exceptional catalytic material for the one-pot oxidation-Knoevenagel condensation reaction.

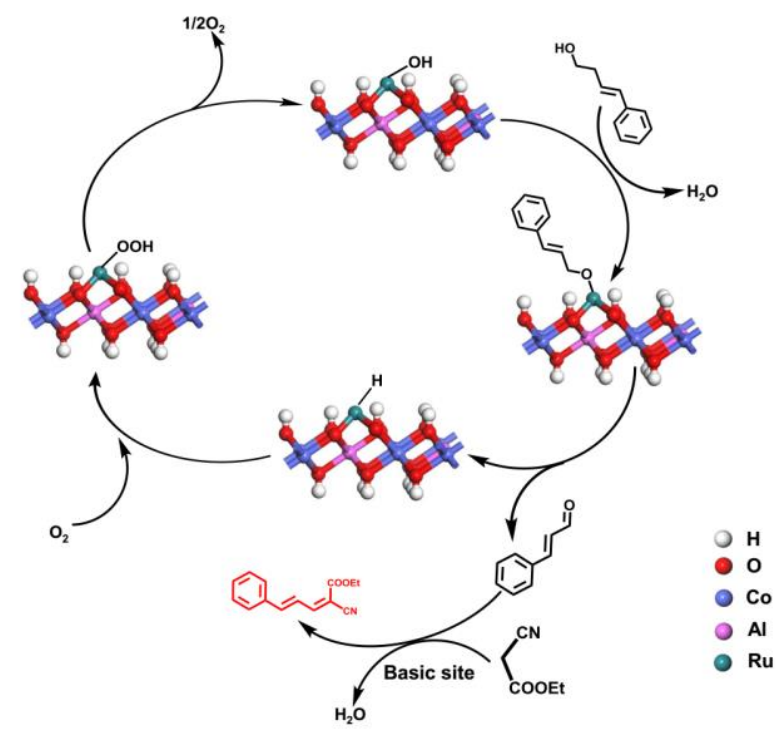

Scheme 2. Reaction pathway of the one-pot reaction over the Ru/LDH-GO-P catalyst.

Based on the discussed experimental evidence, we proposed a possible pathway for the one-pot reaction over the $\mathrm{Ru} / \mathrm{LDH}-\mathrm{GO}-\mathrm{P}$ catalyst (Scheme 2). At the beginning of the reaction, the substrate of cinnamyl alcohol interacted primarily with the basic $\mathrm{Ru}-\mathrm{OH}$ active sites coupled with elimination of hydroxyl protons from cinnamyl alcohol, leading to the formation of an alkoxide intermediate. ${ }^{[1 a]}$ Subsequently, the intermediate formed a highly reactive metal-alcoholate moiety that was able to eliminate $\mathrm{H}$, forming cinnamaldehyde. Then, the basic sites of the LDH catalyzed the Knoevenagel condensation of nitriles with aldehydes to form cinnamylidene ethyl cyanoacetate. The final step involved the rapid oxidation of the $\mathrm{Ru}-\mathrm{H}$ species by the molecular $\mathrm{O}_{2}$ to form $\mathrm{Ru}-\mathrm{OH}$ active sites that completed the catalytic cycle.

In order to evaluate the general applicability and efficiency of the Ru/LDH-GO-P as 
heterogeneous catalyst in one-pot oxidation-Knoevenagel condensation reactions, we investigated the conversion of various benzyl alcohol derivatives and active methylene compounds (Table 3). The $\mathrm{Ru} / \mathrm{LDH}-\mathrm{GO}-\mathrm{P}$ proved to be effective for a variety of benzyl alcohols with either an electron-withdrawing or an electron-donating group (entries 5-9). Herein, $p$-Cl, $p$-Br, $p$-methyl, $p$-nitro, and $p$-methoxy substituted benzyl alcohols were transformed to the desired products with high yields (entries 5-9), although nitro group, $\mathrm{Cl}$, and $\mathrm{Br}$ were strong electron withdrawing groups and methoxy and methyl groups exhibited electron-donating properties. In addition, malononitrile, which was used as the active methylene compound in the condensation reactions with benzyl alcohol derivatives, was also converted to the corresponding condensation products in high yields (entries 2, 4). It should be noted that malononitrile showed higher reactivity compared to the ethyl cyanoacetate in the condensation reaction with the carbonyl substrates.

Table 3. One-pot oxidation-Knoevenagel cascade reactions towards different substrates using Ru/LDHGO-P as the catalyst.

\begin{tabular}{|c|c|c|c|c|c|}
\hline Entry & $\mathbf{A}$ & $\mathbf{R}_{\mathbf{2}}$ & Time & Conv. (\%) & Yield (\%) \\
\hline 1 & & COOEt & $3 \mathrm{~h}$ & 99.5 & 99.5 \\
\hline 2 & & $\mathrm{CN}$ & $2.5 \mathrm{~h}$ & 98.0 & 98.0 \\
\hline 3 & & COOEt & $2 \mathrm{~h}$ & 96.5 & 96.5 \\
\hline 4 & & $\mathrm{CN}$ & $2 \mathrm{~h}$ & 99.0 & 99.0 \\
\hline 5 & & COOEt & $2 \mathrm{~h}$ & 95.0 & 95 \\
\hline 6 & & COOEt & $2 \mathrm{~h}$ & 93.9 & 93.9 \\
\hline 7 & & COOEt & $2 \mathrm{~h}$ & 90.7 & 90.7 \\
\hline 8 & & COOEt & $2 \mathrm{~h}$ & 94.6 & 94.6 \\
\hline 9 & & COOEt & $2 \mathrm{~h}$ & 92.1 & 92.1 \\
\hline
\end{tabular}

\section{Conclusion}


Two new heterogeneous catalysts of Ru/LDH-GO-P and $\mathrm{Ru} / \mathrm{LDH}-\mathrm{GO}-\mathrm{V}$ were successfully synthesized by single-drop method and co-precipitation method, respectively. Experimental data revealed that in the case of Ru/LDH-GO-P, LDH layers were developed with their ab-planes parallel to the GO surface, whereas the ab-planes were found to be oriented perpendicular to GO surface for Ru/LDH-GO-V. XANES studies indicated that the $\mathrm{Ru} / \mathrm{LDH}-\mathrm{GO}-\mathrm{P}$ incorporated more $\mathrm{Co}$ and $\mathrm{O}$ vacancies than $\mathrm{Ru} / \mathrm{LDH}-\mathrm{GO}-\mathrm{V}$.

By taking the one-pot oxidation-Knoevenagel condensation of cinnamyl alcohol and ethyl cyanoacetate as a probe reaction, the Ru/LDH-GO-P showed excellent catalytic performance with the conversion and selectivity $>99 \%$ for the cascade reactions at $333 \mathrm{~K}$ under $\mathrm{O}_{2}$ atmosphere within $3 \mathrm{~h}$, while the $\mathrm{Ru} / \mathrm{LDH}-\mathrm{GO}-\mathrm{V}$ showed $60.7 \%$ conversion and $47.9 \%$ selectivity under the same experimental condition. The observed dramatic difference of the catalytic performance can be attributed to the following reasons. Firstly, the $\mathrm{Co}^{3+}$ centers in $\mathrm{Ru} / \mathrm{LDH}-\mathrm{GO}-\mathrm{P}$ can promote the formation of surface oxygen vacancies that can adsorb and activate $\mathrm{O}_{2}$ to get better performance; Secondly, the Ru/LDH-GO-P exhibited larger BET surface and more medium-strong basic active sites than the Ru/LDH-GO-V. Moreover, the Ru/LDH-GO-P catalyst exhibited wide-range applicability in a variety of aromatic alcohols and it can be easily recovered and reused at least five times without obvious deterioration of its catalytic activity. The observed exceptional robustness and efficiency render the $\mathrm{Ru} / \mathrm{LDH}-\mathrm{GO}-\mathrm{P}$ catalyst an exceptional candidate for industrial applications in fine-chemical synthesis.

\section{Conflicts of interest}

The authors declare there are no conflicts of interest.

\section{Acknowledgements}

This research was supported by the National Nature Science Foundation of China (U1707603, 21625101), Beijing Natural Science Foundation (2182047) and the Fundamental Research Funds for the Central Universities (XK1802-6, XK1902, 12060093063). H.N.M acknowledges the financial support from The University of Glasgow. We would like to thank 1W1B beam line of Beijing Synchrotron Radiation Facility (BSRF). 
Keywords: alcohols, cascade reation, graphene oxides, heterogeneous catalysis, layered double hydroxides.

\section{References}

[1] a) K. Motokura, N. Fujita, K. Mori, T. Mizugaki, K. Ebitani, K. Kaneda, J. Am. Chem. Soc. 2005, 127, 9674-9675. b) M. Platon, R. Amardeil, L. Djakovitch, J. C. Hierso, Chem. Soc. Rev. 2012, 41, 3929-3968. c) R. C. Wende, P. R. Schreiner, Green Chem. 2012, 14, 1821-1849.

[2] a) D. B. Ramachary, S. Jain, Org. Biomol. Chem. 2011, 9, 1277-1300. b) Y. Jiang, X. Y. Tang, M. Shi, Chem. Commun. 2015, 51, 2122-2125.

[3] Q. M. Yang, H. Y. Zhang, L. P. Wang, Y. C. Zhang, J. Q. Zhao, ACS Omega 2018, 3, 4199-4212.

[4] D. K. Wang, Z. H. Li, Catal. Sci. Technol. 2015, 5, 1623-1628.

[5] J. S. Wang, F. Z. Jin, H.-C. Ma, X.-B. Li, M.-Y. Liu, J.-L. Kan, G.-J. Chen, Y.-B. Dong, Inorg. Chem. 2016, 55, 6685-6691.

[6] K. Liu, Y. Q. Xu, Z. X. Yao, H. N. Miras, Y.-F. Song, ChemCatChem 2016, 8, 929-937.

[7] Q. Sun, B. Aguila, S. Q. Ma, Mater. Chem. Front. 2017, 1, 1310-1316.

[8] W. Y. Zhou, S. Y. Zhai, J. G. Pan, A. J. Cui, J. F. Qian, M. Y. He, Z. X. Xu, Q. Chen, Asian J. Org. Chem. 2017, 6, 1536-1541.

[9] a) G. L. Fan, F. Li, D. G. Evans, X. Duan, Chem. Soc. Rev. 2014, 43, 7040-7066. b) S. Omwoma, W. Chen, R. Tsunashima, Y. F. Song, Coord. Chem. Rev. 2014, 258-259, 58-71. c) R. Y. Yang, Y. S. Gao, J. Y. Wang, Q. Wang, Dalton Trans. 2014, 43, 10317-10327.

[10] Y. Q. Jia, Y. J. Fang, Y. K. Zhang, H. N. Miras, Y. F. Song, Chem. Eur. J. 2015, 21, 14862-14870.

[11] S. Zhao, J. H. Xu, M. Wei, Y. F. Song, Green Chem. 2011, 13, 384-389.

[12] Q. Wang, D. O'Hare, Chem. Rev. 2012, 112, 4124-4155.

[13] a) E. Angelescu, O. D. Pavel, R. Birjega, R. Zavoianu, G. Costentin, M. Che, Appl. Catal. A. 2006, 308, 13-18. b) M. Yang, J. Liu, Z. Chang, G. R. Williams, D. O’Hare, X. Zheng, X. Sun, X. Duan, J. Mater. Chem. 2011, 21, 14741-14746. c) Y. Kuwahara, K. Tsuji, T. Ohmichi, T. Kamegawa, K. Mori, H. Yamashita, ChemSusChem. 2012, 5, 1523-1532.

[14] J. T. Feng, Y. F. He, Y. N. Liu and D. Q. Li, Chem. Soc. Rev. 2015, 44, 5191-5319.

[15] a) K. Kaneda, T. Yamashita, T. Matsushita, K. Ebitani, J. Org. Chem. 1998, 63, 1750-1751. b) T. Matsushita, K. Ebitani, K. Kaneda, Chem. Commun. 1999, 265-266. c) N. Zhang, Y. Y. Du, M. Yin, C. Y. Guan, J. T. Feng, D. Q. Li, RSC Adv. 2016, 6, 49588-49596.

[16] N. Kakiuchi, Y. Maeda, T. Nishimura, S. Uemura, J. Org. Chem. 2001, 66, 6620.

[17] T. Mitsudome, A. Noujima, T. Mizugaki, K. Jitsukawa, K. Kaneda, Adv. Synth. Catal. 2009, 351, 
1890-1896.

[18] a) J. Y. hang, Y. C. Ding, X. B. Cai, Y. L. Chen, M. Peng,Z. H. Jia, Z. Jiang, P. J. Ren, S. Y. Yao, J. L. Xie, D. Q. Xiao, X. D. Wen, N. Wang, H. Y. Liu, D. Ma, ACS Catal. 2019, 9, 5998-6005. b) L. X. Xia, D. Li, J. Long, F. Huang, L. N. Yang, Y. S. Guo, Z. M. Jia, J. P. Xiao, H. Y. Liu, Carbon 2015, 145, 47-52. c) F. Huang, Y. C. Deng, Y. L. Chen, X. B. Cai, M. Peng, Z. M. Jia, P. J. Ren, D. Q. Xiao, X. D. Wen, N. Wang, H. Y. Liu, D. Ma, J. Am. Chem. Soc. 2018, 140, 13142-13146. d) Z. M. Jia, F. Huang, J. Y. Diao, J. Y. Zhang, J. Wang, D. S. Su, H. Y. Liu, Chem. Commun. 2018, 54, 11168-11171. f) J. Wang, R. Huang, Y. J. Zhang, J. Y. Diao, J. Y. Zhang, H. Y. Liu, D. S. Su, Carbon 2017, 111, 519-528.

[19] S. Huang, G.-N. Zhu, C. Zhang, W. W. Tjiu, Y.-Y. Xia, T. X. Liu, ACS Appl. Mater. Interfaces 2013, 4, 2242-2249.

[20] B. Li, Y. F. Zhao, S. T. Zhang, W. Gao, M. Wei, ACS Appl. Mater. Interfaces 2013, 5, $10233-$ 10239.

[21] a) Y. F. Zhao, P. Y. Chen, B. S. Zhang, D. S. Su, S. T. Zhang, L. Tian, J. Lu, Z. X. Li, X. Z. Cao, B. Y. Wang, M. Wei, D.G. Evans, X. Duan, Chem. Eur. J. 2012, 18, 11949-11958. b) Y. Lee, J. H. Choi, H. J. Jeon, K. M. Choi, J. W. Lee, J.K. Kang, Energy Environ. Sci. 2011, 4, 914-920.

[22] T. N. Lambert, C. A. Chavez, B. Hernandez-Sanchez, P. Lu, N. S. Bell, A. Ambrosini, T. Friedman, T. J. Boyle, D. R. Wheeler, D. L. Huber, J. Phys. Chem. C 2009,113, 19812-19823.

[23] a) V. Chandra, J. Park, Y. Chun, J. W. Lee, I. C. Hwang, K. S. Kim, ACS Nano 2010, 4, 39793986. b) Y. W. Zhu, S. Murali, W. W. Cai, X. S. Li, J. W. Suk, J. R. Potts, R. S. Ruoff, Adv. Mater. 2010, 22, 3906-3924.

[24] S. Huang, G.-N. Zhu, C. Zhang, W. W. Tjiu, Y.-Y. Xia, T. X. Liu, ACS Appl. Mater. Interfaces 2012, 4, 2242-2249.

[25] a) C. Nethravathi, T. Nisha, N. Ravishankar, C. Shivakumara and M. Rajamathi, Carbon 2009, 47, 2054-2059. b) A. B. Bourlinos, D. Gournis, D. Petridis, T. Szabo, A. Szeri and I. Dekany, Langmuir 2003, 19, 6050-6055.

[26] R. F. Xie, G. L. Fan, Q. Ma, L. Yang, F. Li, J. Mater. Chem. A 2014, 2, 7880-7889.

[27] Z. L. Wang, S. M. Xu, Y. Q. Xu, L. Tan, X. Wang, Y. F. Zhao, H. H. Duan,Y. F. Song, Chem. Sci., 2019, 10, 378-384.

[28] Z. B. Lei, L. Lu, X. S. Zhao, Energy Environ. Sci. 2012, 5, 6391-6399.

[29] a) P Li, P. P. Huang, F. F. Wei, Y. B. Sun, C. Y. Cao, W. G. Song, J. Mater. Chem. A 2014, 2, 12739-12745. b) R. Z. Ma, J. B. Liang, K. Takada, T. Sasaki, J. Am. Chem. Soc. 2011, 133, 613620.

[30] Q. Wang, L. F. Chen, S. L. Guan, X. Zhang, B. Wang, X. Z. Cao, Z. Yu, Y. F. He, D. G. Evans, J. T. Feng, D. Q. Li, ACS Catal. 2018, 8, 3104-3115.

[31] a) T. L. Stuchinskaya, M. Musawir, E. F. Kozhevnikova, I. V. Kozhevnikov, J. Catal. 2005, 231, 41-47. b) Y. B Yu, T. Takei, H. Ohashi, H. He, X. L. Zhang and M. Haruta, J. Catal. 2009, 267, 121-128. 
[32] D. J. Morgan, Surf. Interface Anal. 2015, 47, 1072-1079.

[33] a) J. Zhang, W. J. Yan, Z. An, H. Y. Song, J. He, ACS Sus. Chem. Eng. 2018, 6, 7313-7324. b) H. Chen, S. He, M. Xu, M. Wei, D. G. Evans, X. Duan, ACS Catal. 2017, 7, 2735-2743. c) O. D. Pavel, D. Tichit, I. C. Marcu, Appl. Clay Sci. 2012, 61, 52-58.

[34] a) J. C. Lavalley, Catal. Today 1996, 27, 377-401. b) J. Di Cosimo, V. Díez, M. Xu, E. Iglesia, C. R. Apesteguía, J. Catal. 1998, 178, 499-510.

[35] Y. T. Chen, H. J. Zheng, Z. Guo, C. M. Zhou, C. Wang, A. Borgna, Y. H. Yang, J. Catal. 2011, $283,34-44$.

[36] W. J. Ang, Y. S. Chng, Y. Lam, RSC Adv. 2015, 5, 81415-81428.

[37] C. S. Hinde, W. R. Webb, B. K. J. Chew, H. R. Tan, W.-H. Zhang, T. S. Andy Horbd, R. Raja, Chem. Commun. 2016, 52, 6557-6560.

[38] H. F. Wang, C. Y. Wang, Y. F. Yang, M. Zhao, Y. J. Wang, Catal. Sci. Technol. 2017, 7, 405-417.

[39] N. Zohreh, M. Tavakolizadeh, S. H. Hosseini, A. Pourjavadi, C. Bennett, Polymer 2017, 112, 342350 . 